\title{
Celecoxib induces apoptosis and cell-cycle arrest in nasopharyngeal carcinoma cell lines via inhibition of STAT3 phosphorylation
}

\author{
Dong-bo LIU, Guang-yuan HU, Guo-xian LONG, Hong QIU, Qi MEI, Guo-qing HU*
}

Cancer Center, Tongji Hospital, Tongji Medical College, Huazhong University of Science and Technology, Wuhan 430030, China

\begin{abstract}
Aim: To investigate the mechanisms underlying the anticancer effect of celecoxib on nasopharyngeal carcinoma (NPC).
Methods: NPC cell lines, HNE1 and CNE1-LMP1, were treated with various concentrations of celecoxib for $48 \mathrm{~h}$. The antiproliferative effect of celecoxib was assessed using MTT assay. Both cell cycle profiles and apoptosis were analyzed using flow cytometry. Western blot was used to measure the levels of signal transducer and activator of transcription 3 (STAT3), phosphorylated STAT3 ${ }^{\text {Y705 }}$ (pSTAT3 ${ }^{\mathrm{Y705}}$ ), COX-2, Survivin, Mcl-1, Bcl-2 and Cyclin D1.

Results: Celecoxib (10-75 $\mathrm{mmol} / \mathrm{L}$ ) inhibited the proliferation of the NPC cell lines in a dose-dependent manner. Celecoxib (25 and 50 $\mu \mathrm{mol} / \mathrm{L}$ ) induced apoptosis and cell-cycle arrest at the $\mathrm{G}_{0} / \mathrm{G}_{1}$ checkpoint in the NPC cell lines, which was associated with significantly reduced STAT3 phosphorylation. The genes downstream of STAT3 (ie, Survivin, Mcl-1, Bcl-2 and Cyclin D1) were significantly down-regulated after exposure to celecoxib (25 and $50 \mu \mathrm{mol} / \mathrm{L})$.

Conclusion: The anticancer effects of celecoxib on NPC cell lines results from inducing apoptosis and cell cycle arrest, which may be partly mediated through the STAT3 pathway.
\end{abstract}

Keywords: celecoxib; nasopharyngeal carcinoma; apoptosis; cell cycle; STAT3

Acta Pharmacologica Sinica (2012) 33: 682-690; doi: 10.1038/aps.2012.18; published online 16 Apr 2012

\section{Introduction}

Nasopharyngeal carcinoma (NPC) is the most common head and neck cancer in Southeast Asia and South China. The annual incidence rate of NPC in endemic areas is approximately 20 to 50 per 100000 individuals $^{[1]}$. NPC is characterized by its highly invasive and metastatic tendencies. Approximately $70 \%$ of NPC patients are initially diagnosed with locally advanced disease. Although aggressive concurrent chemo-radiotherapy is the standard treatment modality for NPC at the locally advanced stage, approximately $30 \%$ to $40 \%$ of NPC patients fail with local recurrence and/or distant metastasis ${ }^{[2]}$. The reported median survival time for an NPC patient with metastatic or advanced disease is only 5 to 11 months ${ }^{[3]}$. Due to the poor survival rate, more effective strategies and drugs to prevent and treat NPC are needed. The selective cyclooxygenase-2 (COX-2) inhibitor celecoxib shows great promise in this respect.

Celecoxib was the first COX-2-selective nonsteroidal anti-

\footnotetext{
* To whom correspondence should be addressed.

E-mail gqhu@tjh.tjmu.edu.cn

Received 2011-12-13 Accepted 2012-02-07
}

inflammatory drug (NSAID) approved for the clinical treatment of adult arthritis. Celecoxib exerts potent anticancer activities against various human cancers, including brain, lung, colon and liver cancers ${ }^{[4-7]}$. One mechanism through which celecoxib acts to reduce cancer development is by the inhibition of COX-2 activity. Furthermore, celecoxib can also act through COX-2-independent mechanisms involving the arrest of cell cycle progression, angiogenesis and the induction of apoptosis ${ }^{[8]}$. COX-2 is overexpressed in $43 \%$ to $75 \%$ of NPCs, contributes to nodal metastases and is associated with poorer prognosis ${ }^{[9,10]}$. Although some studies have demonstrated certain antitumor effects of celecoxib on NPC in vitro, the molecular mechanisms underlying its inhibitory effects are still unclear ${ }^{[11-13]}$.

Signal transducer and activator of transcription 3 (STAT3) is constitutively activated or overexpressed in a variety of human cancers. This pivotal transcription factor plays a significant role in regulating cell growth, apoptosis, angiogenesis, immune escape, invasion and metastasis. Accumulating evidence has demonstrated that STAT3 is a promising molecule target for anticancer treatment and cancer prevention ${ }^{[14,15]}$. More recently, STAT3 has also been found to be activated in 
more than $75 \%$ of NPC cases, and this molecule plays a significant role in driving NPC progression and metastasis ${ }^{[16-18]}$. A recent study identified celecoxib as a novel inhibitor of STAT ${ }^{[6]}$. Celecoxib was demonstrated and verified to have specificity to STAT3, and this drug has been shown to exert anticancer effects in colon cancer cells, hepatocellular carcinoma cells and rhabdomyosarcoma cells through the inhibition of STAT3 phosphorylation ${ }^{[6,7,19]}$.

In contrast to other head and neck cancers, NPC possesses the unique feature of being strongly associated with the Epstein-Barr virus (EBV). In EBV-endemic regions, most NPC patients are EBV-infected ${ }^{[20]}$. Latent membrane protein 1 (LMP1), LMP2A, Epstein-Barr nuclear antigen 1 (EBNA1), BamH I-A rightward transcripts (BARTs) and Epstein-Barr virus-encoded RNAs (EBERs) are expressed in EBV. LMP1 is the principal oncoprotein expressed by EBV, and LMP1 protein expression is detected in more than $70 \%$ of NPC patients. LMP1 plays an important role in the tumorigenesis and development of NPC and contributes to the promotion of invasion and metastasis ${ }^{[21]}$. Moreover, a recent study demonstrated that LMP1 could induce STAT3 phosphorylation through the mitogen-activated protein kinase (MAPK)/extracellular signal-regulated kinase (ERK) and Janus kinase (JAK)/STAT pathways $^{[22]}$.

Given the importance of STAT3 in NPC progression and the potent anticancer effect of celecoxib, we chose to investigate the potential molecular mechanisms of this drug with an emphasis on determining whether celecoxib inhibits STAT3 phosphorylation in NPC cells. We also explored whether the anticancer effects of celecoxib may be due to the induction of apoptosis and cell cycle arrest.

\section{Materials and methods}

\section{Chemicals and antibodies}

Lyophilized celecoxib was purchased from Sigma Chemical $\mathrm{Co}, \mathrm{MO}, \mathrm{USA}$. Stock celecoxib solutions were prepared by dissolving the powder in DMSO and then storing at $-20{ }^{\circ} \mathrm{C}$. The drugs were freshly diluted into culture medium before the commencement of each experiment, and the final DMSO concentration in the culture medium never exceeded $0.1 \%$. Primary antibodies including rabbit anti-human phsopho-STAT3Tyr705, Survivin, Mcl-1 and Cyclin D1 monoclonal antibodies were purchased from Epitomics Inc, Burlingame, CA, USA. Rabbit anti-human Bcl-2 and STAT3 monoclonal antibodies were obtained from Cell Signaling Technology, Danvers, USA. Goat anti-human COX-2 and rabbit anti-human $\beta$-actin polyclonal antibodies were obtained from Santa Cruz Biotechnology, USA. The horseradish peroxidase (HRP)-conjugated goat anti-rabbit and HRP-conjugated rabbit anti-goat secondary antibodies were obtained from Santa Cruz Biotechnology. The 3-(4, 5-dimethylthiazol-2-yl)-2, 5-diphenyltetrazolium bromide (MTT) was obtained from Sigma.

\section{Cell culture}

HNE1 was derived from a poorly differentiated NPC that has lost the EB virus due to long-term in vitro passaging (over 100 passages ${ }^{[23]}$. CNE1 is a poorly differentiated NPC cell line that is also EBV negative. CNE1-LMP1 is a stably transfected cell line established by introducing LMP1 cDNA into CNE1 cells $^{[24]}$. The HNE1 and CNE1-LMP1 cell lines were provided by the Cancer Research Institute of Central South University (Changsha, China). All lines were maintained in Roswell Park Memorial Institute (RPMI)-1640 medium (Gibco, Grand Island, USA) supplemented with 10\% newborn calf serum (Gibco, Grand Island, USA) and incubated in a $5 \% \mathrm{CO}_{2}$ atmosphere.

\section{Growth inhibition assay}

The antiproliferative effect of celecoxib on NPC cells was assessed using an MTT assay. Cells were seeded into 96-well plates and allowed to attach for $24 \mathrm{~h}$. The cells were then treated with increasing concentrations of celecoxib $(0,5,10$, 25, 50 or $75 \mu \mathrm{mol} / \mathrm{L}$ ) dissolved in DMSO (final concentration $\leq 0.1 \%$ ) and incubated for up to $48 \mathrm{~h}$. After the incubation, 20 $\mu \mathrm{L}$ of MTT dye $(5 \mathrm{mg} / \mathrm{mL})$ were added to each well and cells were incubated at $37^{\circ} \mathrm{C}$ for $4 \mathrm{~h}$. After removing the supernatants, the crystals were dissolved in DMSO and the absorbance was measured at $490 \mathrm{~nm}$. The percentage growth inhibition was calculated as $\left(O D_{\text {control }}-O D_{\text {drug }}\right) / O D_{\text {control }} \times 100 \%$. The halfmaximal inhibitory concentration $\left(\mathrm{IC}_{50}\right)$ values and the $95 \%$ confidence intervals were calculated using probit regression using SPSS 15.0 software (SPSS Inc, Chicago, IL, USA). The experiment was performed in triplicate and repeated at least three times.

\section{Apoptosis assay}

Cells were treated with increasing doses of celecoxib $(0,10,25$, 50 or $75 \mu \mathrm{mol} / \mathrm{L}$ ) for $48 \mathrm{~h}$ and then harvested and washed with phosphate buffered saline (PBS). After washing, the cells were stained with Annexin V-fluorescein isothiocyanate (FITC) and propidium iodide (PI) for $15 \mathrm{~min}$ at $4{ }^{\circ} \mathrm{C}$ in the dark, in accordance with the manufacturer's instructions (Nanjing KeyGen Biotech Co, Nanjing, China). After incubation, the cells were immediately analyzed using flow cytometry (EPICS XL, Beckman Coulter Inc, Fullerton, CA, USA). Early apoptotic cells stained positive for Annexin V-FITC and negative for PI. Late apoptotic cells were positive for both Annexin V-FITC and PI. The experiment was performed in triplicate and repeated at least three times.

\section{Cell cycle analysis}

Cells were treated with increasing concentrations of celecoxib $(0,10,25,50$ or $75 \mu \mathrm{mol} / \mathrm{L})$ for $48 \mathrm{~h}$. The adherent and the nonadherent cell fractions were then collected and fixed in $70 \%$ ice-cold ethanol overnight. Cells were washed with cold PBS, treated with RNase for $30 \mathrm{~min}$ at $37^{\circ} \mathrm{C}$, and then stained with PI for 30 min at $4{ }^{\circ} \mathrm{C}$ in the dark. DNA content was analyzed using flow cytometry (EPICS XL, Beckman Coulter Inc, Fullerton, CA, USA). The data were analyzed using the Mod$\mathrm{Fit}^{\mathrm{TM}}$ for Mac version 3.0 software (Verity Software House, Topsham, ME, USA). The experiment was performed in triplicate and repeated at least three times. 


\section{Western blot analysis}

Cells were treated with DMSO (control) or increasing concentrations of celecoxib $(10,25,50$ or $75 \mu \mathrm{mol} / \mathrm{L})$ for $48 \mathrm{~h}$. The cells were then washed with PBS and lysed in Radio-Immunoprecipitation Assay (RIPA) buffer with phosphatase and protease inhibitors (Roche Diagnostics, Mannheim, Germany). The protein concentrations were determined using the Bradford protein assay kit (Bio-Rad Laboratories Inc, Hercules, CA, USA) according to the manufacturer's instructions. Protein samples were separated by sodium dodecylsulfate-polyacrylamide gel electrophoresis (SDS-PAGE) and transferred to polyvinylidene difluoride (PVDF) membranes (Millipore, Billerica, MA, USA). After blocking the membrane's nonspecific binding sites using non-fat milk, the membranes were separately incubated with primary antibodies overnight and then probed with HRP-conjugated goat anti-rabbit or HRPconjugated rabbit anti-goat secondary antibodies. The specific proteins of interest were visualized using the enhanced chemiluminescence (ECL) detection system. Densitometric quantification of the bands was performed using the AlphaEaseFC software tool (Alpha Innotech, San Leandro, CA, USA). The experiment was performed in triplicate and repeated at least three times.

\section{Statistical analysis}

All data were expressed as the mean \pm standard deviations (SD). Statistical analysis was performed using Student's $t$ test. $P<0.05$ was considered statistically significant.

\section{Results}

COX-2 protein expression in NPC cell lines

To investigate the COX-2 protein expression patterns in HNE1 and CNE1-LMP1 cells, Western blots were performed after $48 \mathrm{~h}$ incubations with different doses of celecoxib $(0,10,25$, 50 or $75 \mu \mathrm{mol} / \mathrm{L})$. Western blot analysis revealed that both cell lines expressed COX-2. The HNE1 cells exhibited higher protein expression levels of COX-2 than the CNE1-LMP1 cells $(P<0.01)$. In the HNE1 cell line, COX-2 expression was significantly down-regulated upon celecoxib treatment at concentrations of 10,25 and $50 \mu \mathrm{mol} / \mathrm{L}(P<0.01, P<0.01$ and $P<0.01$, respectively). However, at the 50 and $75 \mu \mathrm{mol} / \mathrm{L}$ concentrations of celecoxib in CNE1-LMP1 cells, COX-2 expression was significantly up-regulated $(P<0.01$ and $P<0.01$, respectively) (Figure $1 \mathrm{~A}$ and $1 \mathrm{~B}$ ).

\section{Anti-proliferative effect of celecoxib on NPC cell lines}

To investigate whether celecoxib was capable of inhibiting NPC cell growth, HNE1 and CNE1-LMP1 cells were treated with increasing concentrations of celecoxib $(0,5,10,25,50$ or $75 \mu \mathrm{mol} / \mathrm{L}$ ) for $48 \mathrm{~h}$, followed by an MTT assay. As shown in Figure 1C and 1D, we observed that the inhibitory effect of celecoxib occurred in a dose-dependent manner. The average $\mathrm{IC}_{50}$ values of celecoxib in HNE1 and CNE1-LMP1 were $32.86 \pm 1.13 \mu \mathrm{mol} / \mathrm{L}$ and $61.31 \pm 4.30 \mu \mathrm{mol} / \mathrm{L}$, respectively.
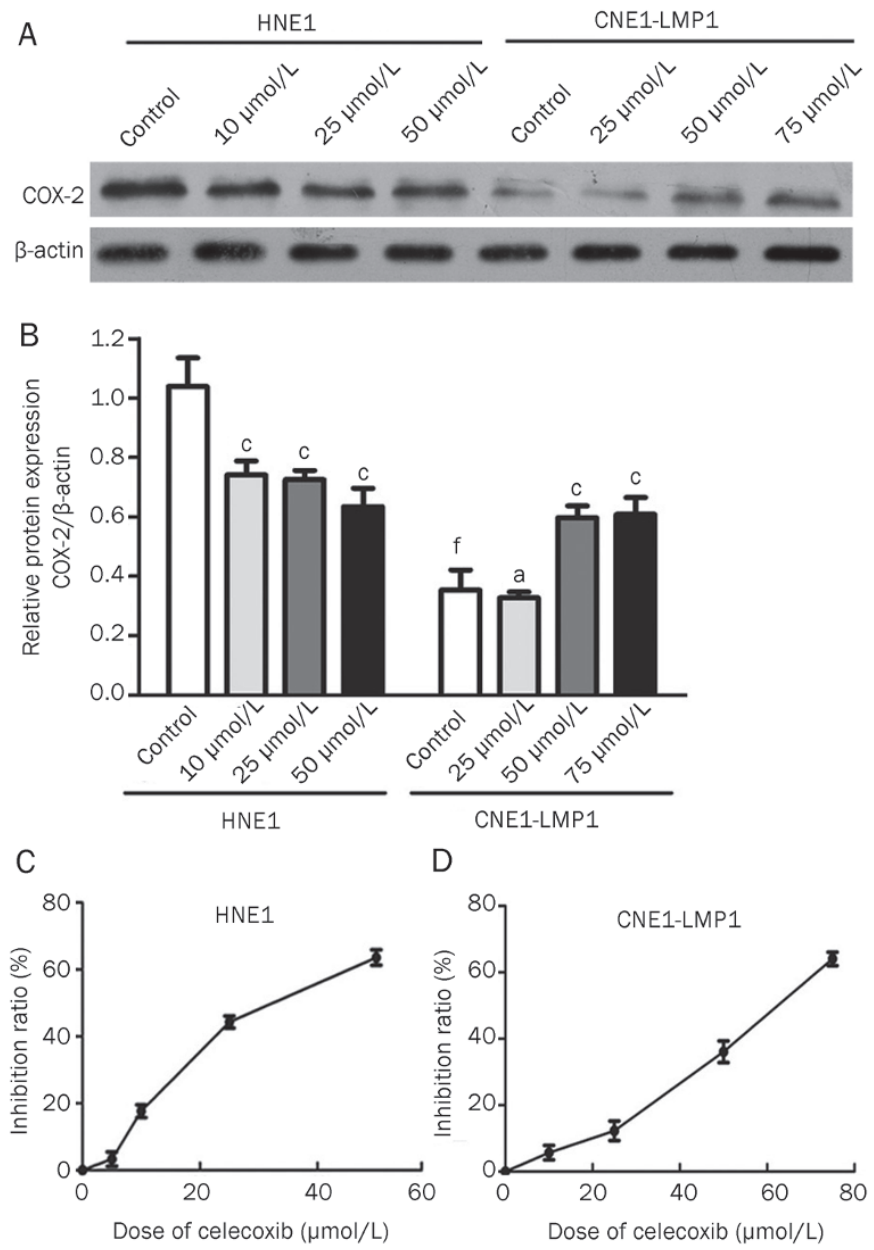

Figure 1. Celecoxib regulated COX-2 expression levels and inhibited cell proliferation in human nasopharyngeal carcinoma cells. (A and $B$ ) COX-2 was consistently expressed in both HNE1 and CNE1-LMP1 cell lines. Western blot analysis of the control cells and cells treated with various concentrations celecoxib $(0,10,25,50$ or $75 \mu \mathrm{mol} / \mathrm{L})$. HNE1 cells expressed higher levels of COX-2 than CNE1-LMP1 cells. COX-2 expression levels were significantly reduced in HNE1 cells but were significantly increased in the CNE1-LMP1 cells after drug treatment. (C and D) Celecoxib induced dose-dependent growth inhibition in both HNE1 and CNE1-LMP1 cells. Values displayed are the mean \pm SD $(n=3) .{ }^{a} P>0.05$, ${ }^{c} P<0.01$ vs control; ${ }^{\mathrm{f}} P<0.01$ CNE1-LMP1 control vs HNE1 control.

\section{Celecoxib induces apoptosis in NPC cell lines}

Because celecoxib has been reported to exert an anticancer effect by mediating apoptosis in a COX-2-independent manner in many tumors ${ }^{[25]}$, we examined whether the inhibitory effect of celecoxib was associated with the induction of apoptosis. Flow cytometric analysis using Annexin V/PI double staining in both celecoxib-treated and control cells was used to detect apoptosis. After treatment with increasing doses of celecoxib $(0,10,25,50$ or $75 \mu \mathrm{mol} / \mathrm{L})$ for $48 \mathrm{~h}$, induction of apoptosis was observed in both HNE1 and CNE1-LMP1 cells in a concentration-dependent manner. Celecoxib induced significant increases in the percentage apoptotic cells in HNE1 cells 
at concentrations of 25 and $50 \mu \mathrm{mol} / \mathrm{L}(P<0.01$ and $P<0.01$, respectively) and in CNE1-LMP1 cells at concentrations of 50 and $75 \mu \mathrm{mol} / \mathrm{L}(P<0.05$ and $P<0.01$, respectively) (Figure 2$)$.
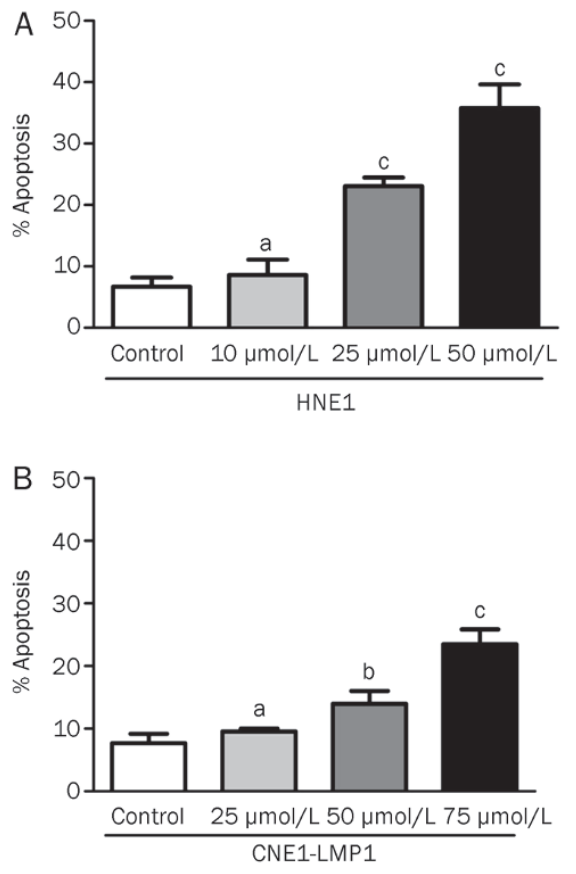

Figure 2. Celecoxib induced apoptosis in HNE1 and CNE1-LMP1 cells. After $48 \mathrm{~h}$ of incubation with drugs, flow cytometry analysis using Annexin $V$ and propidium iodide (PI) double staining was performed on both control and celecoxib-treated cells. The population in the figure is the total number of apoptotic cells, which includes both early and late apoptotic populations. Early apoptotic cells were positive for Annexin V-FITC and negative for PI. Late apoptotic cells were positive for both Annexin V-FITC and PI. Significant apoptosis was observed in HNE1 cells (A) with 25 and $50 \mu \mathrm{mol} / \mathrm{L}$ of celecoxib, and in CNE1-LMP1 cells (B) with 50 and 75 $\mu \mathrm{mol} / \mathrm{L}$ of celecoxib. The data are presented as the mean $\pm \operatorname{SD}(n=3)$. ${ }^{\mathrm{a}} \mathrm{P}>0.05,{ }^{\mathrm{b}} \mathrm{P}<0.05,{ }^{\mathrm{c}} \mathrm{P}<0.01$ vs control.

\section{Celecoxib induces cell-cycle arrest in NPC cell lines}

To investigate whether cell-cycle arrest contributed to cell growth inhibition by celecoxib, cell-cycle progression was assayed. Flow cytometric analysis was performed on NPC cells treated with increasing concentrations of celecoxib (0, 10, 25, 50 or $75 \mu \mathrm{mol} / \mathrm{L})$ for $48 \mathrm{~h}$. As displayed in Figure 3, celecoxib induced a marked $\mathrm{G}_{0} / \mathrm{G}_{1}$ cell-cycle arrest in NPC cell lines in a concentration-dependent manner. Compared with the DMSO control treatment group, a significant increase in the $\mathrm{G}_{0} / \mathrm{G}_{1}$ population was observed in both NPC cell lines. At 25 and $50 \mu \mathrm{mol} / \mathrm{L}$ concentrations of celecoxib, significant increases $(P<0.01$ and $P<0.01$, respectively) in the proportion of cells arrested in the $G_{0} / G_{1}$ cell-cycle phase were observed in HNE1 cells. Subsequently, significant inhibition of $S$ phase transition $(P<0.01$ and $P<0.01$ at 25 and $50 \mu \mathrm{mol} / \mathrm{L}$, respectively) and $\mathrm{G}_{2} / \mathrm{M}$ phase $(P<0.05$ and $P<0.01$ at 25 and 50 $\mu \mathrm{mol} / \mathrm{L}$, respectively) were observed. In CNE1-LMP1 cells there were significant increases in the proportion of cells that were arrested in the $\mathrm{G}_{0} / \mathrm{G}_{1}$ phase of the cell cycle after celecoxib treatment at concentrations of 25, 50 and $75 \mu \mathrm{mol} / \mathrm{L}$ $(P<0.01, P<0.01$ and $P<0.01$, respectively). Subsequently, significant inhibition of $S$ phase transition $(P<0.05$ and $P<0.01$ at 50 and $75 \mu \mathrm{mol} / \mathrm{L}$, respectively) and $\mathrm{G}_{2} / \mathrm{M}$ phase $(P<0.01$ and $P<0.01$ at 50 and $75 \mu \mathrm{mol} / \mathrm{L}$, respectively) were observed (Figure $3 \mathrm{~B}$ and $3 \mathrm{C})$.

\section{Celecoxib inhibits STAT3 phosphorylation}

To investigate whether celecoxib could inhibit STAT3 phosphorylation, Western blotting was used to analyze the levels of phosphorylated STAT3 after celecoxib treatment. The HNE1 and CNE1-LMP1 cell lines were treated with increasing concentrations of celecoxib $(0,10,25,50$ or $75 \mu \mathrm{mol} / \mathrm{L})$. As displayed in Figure 4, we observed that the amount of phosphorylated STAT3 ${ }^{\mathrm{Y} 705}$ (pSTAT3) was significantly reduced after the treatment of celecoxib at concentrations of 10, 25 or $50 \mu \mathrm{mol} / \mathrm{L}(P<0.01, P<0.01$ and $P<0.01$, respectively) in HNE1 cells. Additionally, phosphorylated STAT3 ${ }^{\mathrm{Y} 705}$ was significantly down-regulated in CNE1-LMP1 cells after celecoxib treatment at concentrations of 25,50 and $75 \mu \mathrm{mol} / \mathrm{L}(P<0.01$, $P<0.01$ and $P<0.01$, respectively). The pSTAT3 expression levels in the CNE1-LMP1 cell line were higher than those in the HNE1 cell line $(P<0.01)$ (Figures $4 \mathrm{~A}$ and $4 \mathrm{~B})$, and the amount of total STAT3 expressed was consistent after treatment with increasing celecoxib doses.

To provide further evidence of the inhibition of STAT3 phosphorylation, we analyzed the important downstream proteins of STAT3 by Western blot. Survivin, Mcl-1, Bcl-2 and Cyclin D1 proteins displayed reduced expression levels after treatment with escalating doses of celecoxib $(0,10,25,50$ and $75 \mu \mathrm{mol} / \mathrm{L}$ ) in HNE1 and CNE1-LMP1 cells (Figure 4A). In HNE1 cells, celecoxib significantly down-regulated Survivin $(P<0.01$ and $P<0.01$ at 25 and $50 \mu \mathrm{mol} / \mathrm{L}$, respectively), Mcl-1 ( $P<0.01$ and $P<0.01$ at 25 and $50 \mu \mathrm{mol} / \mathrm{L}$, respectively), Bcl-2 $(P<0.01, P<0.01$ and $P<0.05$ at 10,25 and $50 \mu \mathrm{mol} / \mathrm{L}$, respectively) and Cyclin D1 $(P<0.01, P<0.01$ and $P<0.01$ at 10, 25 and $50 \mu \mathrm{mol} / \mathrm{L}$, respectively). In CNE1-LMP1 cells, Survivin $(P<0.01, P<0.01$ and $P<0.01$ at 25,50 and $75 \mu \mathrm{mol} / \mathrm{L}$, respectively), Mcl-1 $(P<0.01, P<0.01$ and $P<0.01$ at 25, 50 and $75 \mu \mathrm{mol} / \mathrm{L}$, respectively), Bcl-2 $(P<0.01$ and $P<0.01$ at 50 and $75 \mu \mathrm{mol} / \mathrm{L}$, respectively) and Cyclin D1 $(P<0.01, P<0.01$ and $P<0.01$ at 25,50 and $75 \mu \mathrm{mol} / \mathrm{L}$, respectively) were significantly down-regulated after celecoxib treatment (Figure $4 \mathrm{C}$ and 4D). This provides additional evidence that celecoxib inhibits STAT3 phosphorylation.

\section{Celecoxib inhibits interleukin-6 (IL-6)-induced STAT3 phosphoryla-} tion

To investigate whether celecoxib may inhibit interleukin-6 (IL-6)-induced STAT3 phosphorylation, Western blotting was performed. We chose the HNE1 cell line due to its low levels of endogenous pSTAT3 ${ }^{\mathrm{Y705}}$. Cells were cultured in serumfree medium for $24 \mathrm{~h}$ and then pretreated with $25 \mu \mathrm{mol} / \mathrm{L}$ or $50 \mu \mathrm{mol} / \mathrm{L}$ of celecoxib for $2 \mathrm{~h}$. The cells were then treated with 25 ng/mL of human IL-6 (Peprotech Inc, Rocky Hill, NJ, 
A

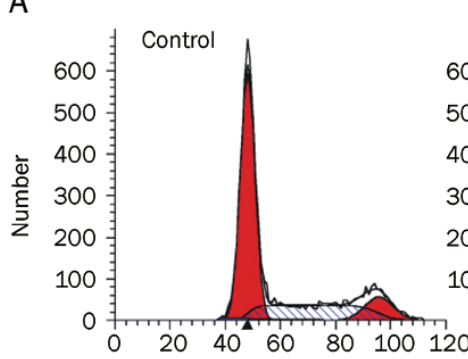

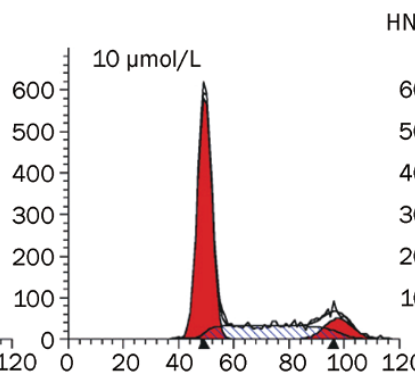

HNE1

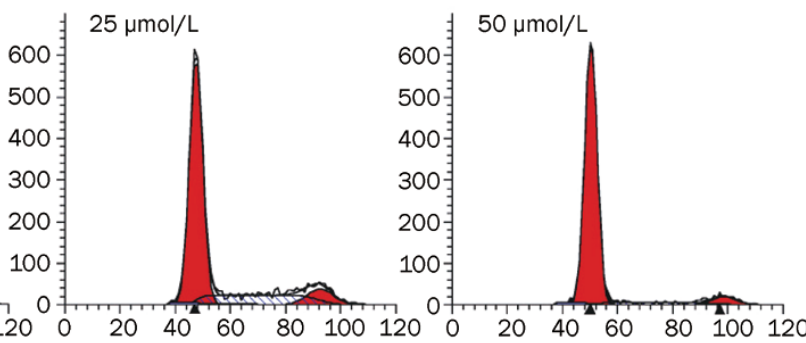

CNE1-LMP1
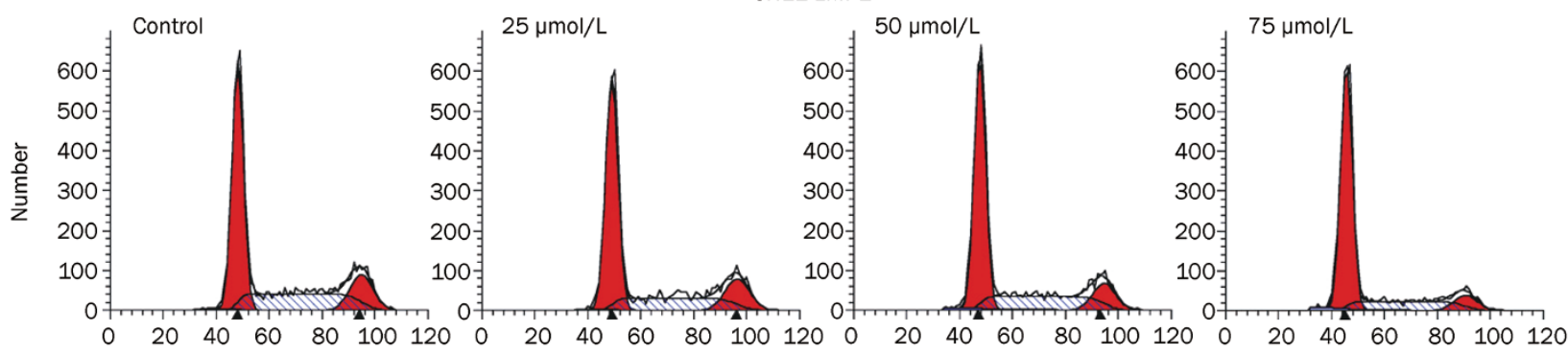

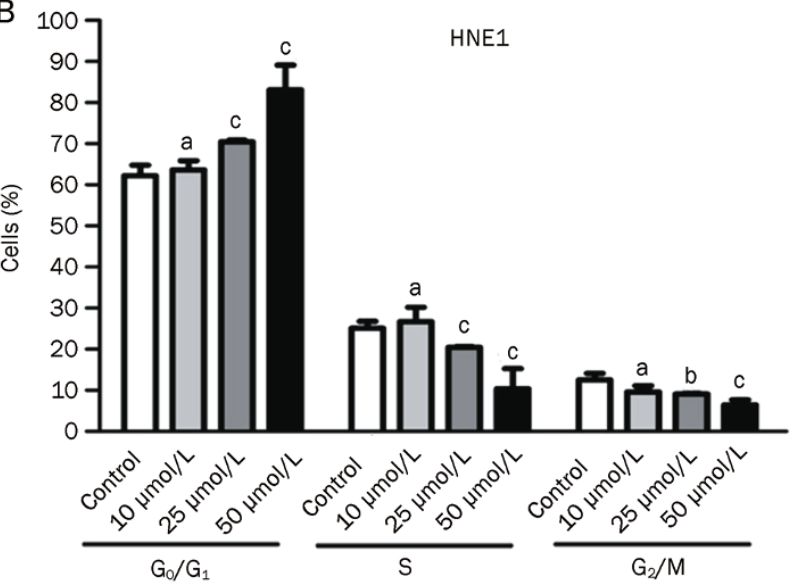

C

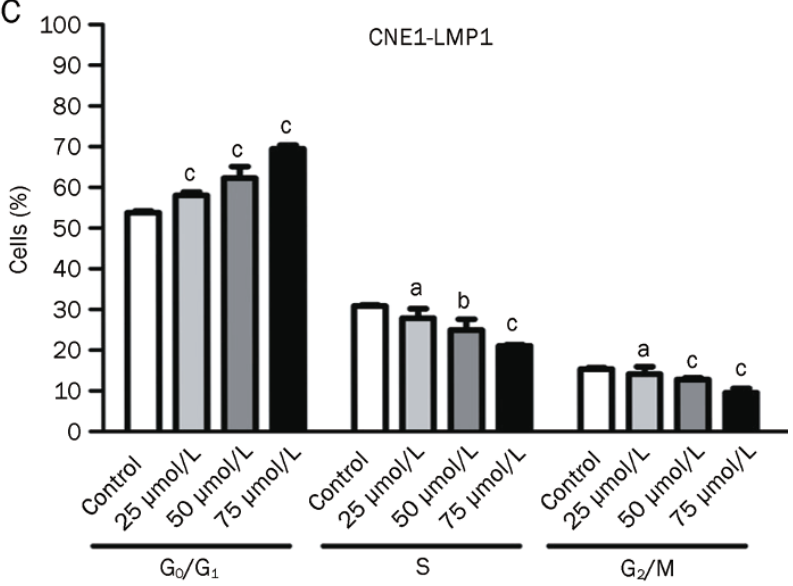

Figure 3. Celecoxib caused cell-cycle arrest in HNE1 and CNE1-LMP1 cells. Flow cytometry analysis of cells treated with DMSO (control) or celecoxib (10, 25,50 or $75 \mu \mathrm{mol} / \mathrm{L}$ ) for $48 \mathrm{~h}$. Cells were fixed with $70 \%$ ethanol, stained with PI, and analyzed by flow cytometry. (A) Representative DNA histogram of cells after treatment with control or various concentrations of celecoxib for $48 \mathrm{~h}$. Significant $\mathrm{G}_{0} / \mathrm{G}_{1}$ checkpoint arrest was observed in $\mathrm{HNE} 1$ (B) treated with 25 and $50 \mu \mathrm{mol} / \mathrm{L}$ of celecoxib, and this arrest was also observed in CNE1-LMP1 cells (C) treated with 25, 50 or $75 \mu \mathrm{mol} / \mathrm{L}$ of celecoxib. The data shown are the mean \pm SD from triplicate replicates and three independent experiments. ${ }^{\mathrm{a}} P>0.05,{ }^{\mathrm{b}} P<0.05,{ }^{\mathrm{c}} P<0.01$ vs control.

USA) for 30 min. After IL-6 treatment, pSTAT3 ${ }^{\mathrm{Y} 705}$ and STAT3 protein levels were analyzed by Western blot. We observed that IL-6 significantly promoted STAT3 phosphorylation $(P<0.01)$ and that celecoxib significantly inhibited IL-6-induced STAT3 phosphorylation at concentrations of 25 and $50 \mu \mathrm{mol} / \mathrm{L}$ $(P<0.01$ and $P<0.01$, respectively) (Figure 5A and 5B).

\section{Discussion}

STAT3 is a novel anticancer drug target. Constitutive STAT3 activation has a critical role in tumor development and tumorigenesis in multiple tumors and cell lines. Critical gene expression changes induced by aberrant activation of STAT3 may promote cancer cell growth and survival via the upregulation of Cyclin D1, c-Myc, Pim-1 ${ }^{[26,27]}$. Additionally, STAT3 may inhibit apoptosis via the upregulation of Bcl-2, Survivin and Mcl-1 ${ }^{[28-30]}$. STAT3 may also promote cancer cell invasion and metastasis through the induction of matrix metalloprateinase-2 $(\mathrm{MMP}-2)^{[31]}$ and increase angiogenesis via the induction of vascular endothelial growth factor (VEGF) and hypoxia-inducible factor 1-alpha (HIF-1a) ${ }^{[32]}$. Increasing evidence has shown that the inhibition of constitutively activated STAT3 could lead to cancer cell death and tumor regression ${ }^{[33-35]}$.

The activation or overexpression of STAT3 is very common in NPC. Indeed, it is detected in more than $75 \%$ of NPC cases. 

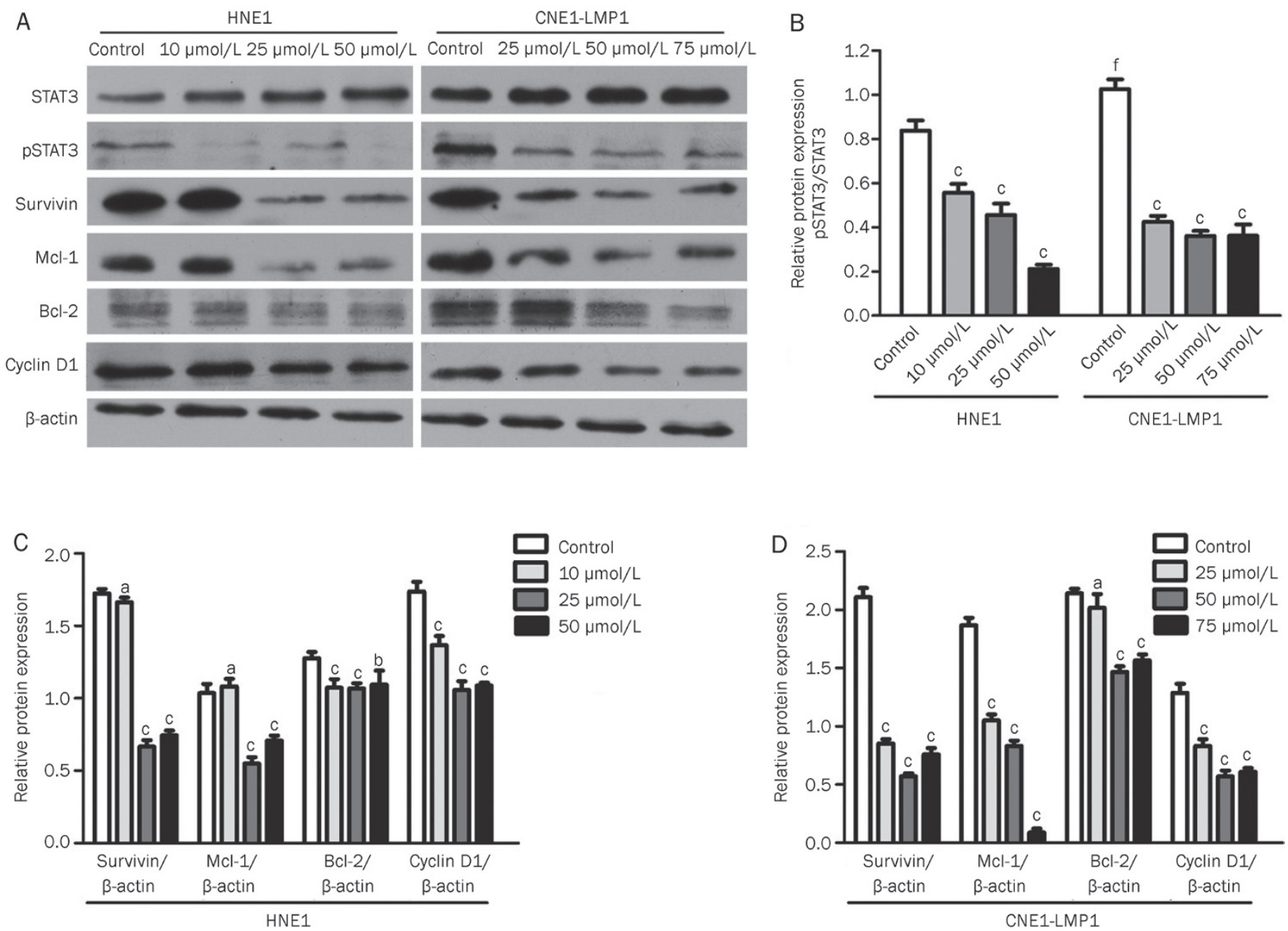

Figure 4. Celecoxib inhibited STAT3 phosphorylation and down-regulated the levels of STAT3 downstream targets. HNE1 and CNE1-LMP1 cells were treated with DMSO (control) or celecoxib $(10,25,50$ or $75 \mu \mathrm{mol} / \mathrm{L})$ for $48 \mathrm{~h}$. Celecoxib significantly inhibited STAT3 phosphorylation in both cell lines. The PSTAT3 expression level was higher in the CNE1-LMP1 cell line than that in the HNE1 cell line (A and B). Celecoxib also down-regulated the downstream proteins of STAT3 (Survivin, Mcl-1, Bcl-2 and Cyclin D1) (C and D). The blots displayed are from a representative experiment repeated three times with similar results. ${ }^{\mathrm{a}} P>0.05,{ }^{\mathrm{b}} P<0.05,{ }^{\mathrm{c}} P<0.01$ vs control; ${ }^{\mathrm{f}} P<0.01$ CNE1-LMP1 control vs HNE1 control.

Growing evidence indicates that STAT3 activation contributes to the progression and invasiveness of $\mathrm{NPC}^{[16-18]}$. Therefore, the activation of STAT3 provides a promising and valid target for NPC therapeutic modalities.

Even though a great number of studies have demonstrated that celecoxib could exert its anticancer effect in a wide variety of tumor types through COX-2-dependent and/or COX-2independent pathways, studies on the anticancer effect and molecular mechanisms of celecoxib in NPC are scarce ${ }^{[11-13]}$. The majority of NPC patients are EBV infected, and LMP1 is the main EBV oncoprotein expressed in these tumors. Therefore, the HNE1 (EBV-negative) and CNE1-LMP1 cell lines were chosen for this study. The results presented in our study clearly illustrate that celecoxib significantly inhibits cell proliferation in both of the NPC cell lines in a dose-dependent manner. However, the mechanism of the anticancer effect of celecoxib is not fully dependent on COX-2 expression. COX-2 protein expression levels in HNE1 cells are higher than in CNE1-LMP1 cells. Additionally, the COX-2 expression pattern was different between the two cell lines after treatment with celecoxib, with down-regulated COX-2 expression observed in HNE1 cells, but up-regulated COX-2 expression in CNE1LMP1 cells. The mechanism for increased COX-2 expression in CNE1-LMP1 cells is still unclear.

The observation that celecoxib can increase COX-2 expression was reported in breast cancer MDA-MB-231 cells, 184 hTERT breast cancer cells and human osteosarcoma MG-63 cells ${ }^{[36-38]}$. One or more products produced by COX may be capable of inhibiting COX expression via a negative feedback loop. Celecoxib treatment could remove the negative feedback and lead to COX-2 induction. In addition, Murono et al determined that LMP1 could induce COX-2 expression in NPC cell lines, increase prostaglandin E2 production through COX-2 induction and that celecoxib could inhibit prostaglandin E2 production ${ }^{[39]}$. Therefore, LMP1 may induce COX-2 expression to up-regulate prostaglandin E2 expression after the inhibition of prostaglandin E2 expression by celecoxib. Furthermore, celecoxib is known to inhibit the phosphatidylinositol 3-kinase 
A

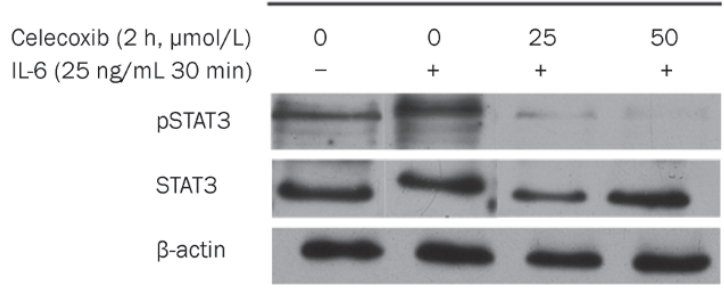

B

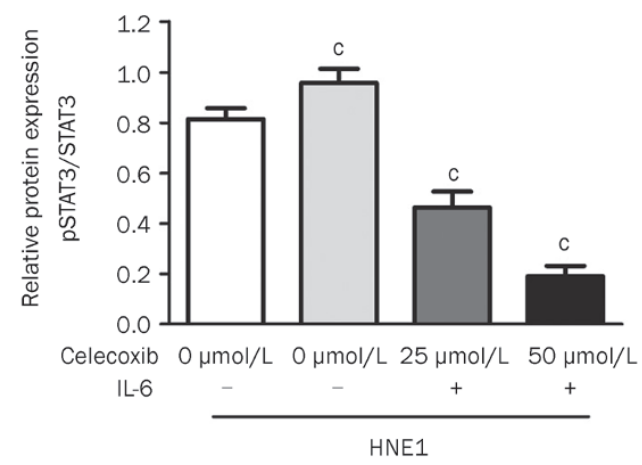

Figure 5. Celecoxib inhibited STAT3 phosphorylation induced by IL-6. HNE1 cells were pretreated with celecoxib for $2 \mathrm{~h}$ followed by $25 \mathrm{ng} / \mathrm{mL}$ of IL-6 for $30 \mathrm{~min}$. Western blot analysis was performed for STAT3 phosphorylation. IL-6 promoted pSTAT3 expression, which was significantly suppressed by celecoxib at concentrations of 25 and $50 \mu \mathrm{mol} / \mathrm{L}$ ( $A$ and $B$ ). The blots displayed are from a representative experiment repeated three times with similar results. ${ }^{c} P<0.01$ vs control.

(PI3K)/Protein Kinase B (Akt) pathway ${ }^{[40]}$. Monick et al reported that $\mathrm{P} 13 \mathrm{~K}$ inhibition resulted in an increase in COX-2 protein ${ }^{[41]}$. PI3K negatively regulates the activation of the p38 pathway, and active p38 is necessary for COX-2 production. Therefore, celecoxib could up-regulate COX-2 expression via the downregulation of PI3K.

Regardless of the COX-2 expression patterns in HNE1 and CNE1-LMP1 cells, at the molecular level, in accordance with the recent similarly reported findings in colon cancer cells, hepatocellular carcinoma cells and rhabdomyosarcoma cells $s^{[6,7,19]}$, celecoxib strongly inhibited STAT3 phosphorylation in both NPC cell lines, which is a critical step in the activation of downstream signaling. pSTAT3 expression levels in CNE1-LMP1 cells were higher than in the HNE1 cells. One potential mechanism for this discrepancy may be that LMP1 could activate STAT3 phosphorylation through the MAPK/ ERK and JAK/STAT pathways ${ }^{[22]}$. Subsequently, the critical downstream proteins Survivin, Mcl-1, Bcl-2 and Cyclin D1, were down-regulated, ultimately leading to cell growth inhibition, cell cycle arrest and apoptosis. To the best of our knowledge, the anticancer effect of celecoxib on the STAT3 signaling cascade in NPC cells has not yet been investigated. Our results revealed that the STAT3 pathway may be a COX-2-independent anticancer mechanism for celecoxib.

IL-6 induces STAT3 phosphorylation in various human cancers $^{[22-44]}$. We hypothesized that celecoxib could exert anticancer effect by blocking inflammatory pathways, such as the IL-6/STAT3 pathway. In agreement with previously published studies ${ }^{[6,7,19]}$, our results indicated that celecoxib could inhibit IL-6-induced STAT3 phosphorylation in HNE1 cells, demonstrating that celecoxib has great promise as a molecular targeting therapy for human cancers with aberrant IL-6 expression.

Studies in various cancers have indicated that celecoxib possesses a unique capacity to induce apoptosis independent of COX-2 inhibition, making celecoxib a potent anticancer drug $^{[8,25]}$. At the cellular level, our results showed that celecoxib induced apoptosis in both the HNE1 and CNE1-LMP1 cell lines and that apoptosis was associated with the downregulation of the anti-apoptotic proteins Survivin, Mcl-1 and Bcl-2. Survivin, Mcl-1 and Bcl-2 are important downstream apoptotic genes in the IL-6/STAT3 pathway. Constitutively active STAT3 up-regulates Survivin, Mcl-1 and Bcl-2, leading to the dysregulation of apoptosis and thereby promoting cancer cell survival and proliferation. The apoptosis induction and the down-regulation of critical downstream anti-apoptotic proteins (Survivin, Mcl-1 and Bcl-2) further indicated that celecoxib could work via the inhibition of STAT3 phosphorylation. Several studies demonstrated that inhibition of 3-phosphoinositide-dependent kinase 1 (PDK-1) and its downstream substrate, $\mathrm{PKB} / \mathrm{AKT}$, plays a central role in the induction of apoptosis and cell cycle arrest $t^{[8]}$. However, whether this is the case in NPC still requires further investigation.

It is well described in the literature that celecoxib inhibits cell growth and survival in several different tumor types through the induction of $G_{0} / G_{1}$ cell cycle arrest. However, no consensus exists concerning the underlying molecular mechanisms of these effects. Consistent with previous studies ${ }^{[36,45,46]}$, our results demonstrated that celecoxib induced $G_{0} / G_{1}$ cell cycle arrest in HNE1 and CNE1-LMP1 cell lines and that this arrest was accompanied by the down-regulation of Cyclin $\mathrm{D} 1^{[12,45-47]}$, which is one of the major cyclins known to be upregulated in cancers. Cyclin D1 activates Cyclin Dependent Kinase 2 (CDK2) and CDK4, leading to the phosphorylation of the retinoblastoma protein $(\mathrm{pRb})$, which forces its release from the E2F transcription factor. Consequently, the cell cycle progresses from $G_{1}$ to $S$ phase ${ }^{[48]}$. In our studies, the celecoxibinduced cell-cycle arrest in $G_{0} / G_{1}$ phase occurred, at least partially, via the downregulation of Cyclin D1 expression. It has been reported in other cancer types that celecoxib induces $\mathrm{G}_{0} / \mathrm{G}_{1}$ cell-cycle arrest by down-regulating c-Myc, Cyclins A and B, up-regulating cell-cycle inhibitors p21 $1^{\text {wafl }}$ and p $27^{\text {kipl }}$ and losing CDK activity ${ }^{[8]}$. It is unclear whether these mechanisms are involved in NPC cells after celecoxib treatment.

In addition to the above work, preclinical findings and a Phase I clinical trial suggest celecoxib could synergistically enhance radiation therapy treatment in prostate, lung and recurrent head and neck cancers ${ }^{[49-51]}$. Radiotherapy (RT) is the primary treatment modality for non-metastatic NPC. A recent Phase I clinical trial in NPC determined that celecoxib can be safely administered concurrently with radiotherapy at doses of up to $800 \mathrm{mg} / \mathrm{d}$ with good rates of local control and overall 
survival ${ }^{[52]}$. However, whether celecoxib improved treatment efficacy is still unclear due to the lack of a control arm. Therefore, further studies are required to investigate whether synergistic effects exist with combination of celecoxib and radiation therapy in NPC in vitro and in vivo and to elucidate the underlying molecular mechanisms of this treatment.

There are certain limitations in the present study. First, different cell lines may respond differently to celecoxib; therefore, additional cell lines must be investigated to fully elucidate the underlying mechanism of the proliferation inhibitory effect with celecoxib treatment. Additionally, further studies are needed to differentiate the anticancer effect of celecoxib in NPC on different pathways. Celecoxib could act through COX-2-dependent and/or COX-2-independent mechanisms, including the COX-2 pathway, the PI3K/AKT pathway, the ERK pathway, the IL-6/STAT3 pathway, and other pathways. Elucidating the precise molecular mechanism would provide a precise molecular target for future NPC therapy. In vivo studies also need to be evaluated.

In summary, at the cellular level, the present study demonstrated that celecoxib inhibited growth and induced apoptosis and cell-cycle arrest at the $\mathrm{G}_{0} / \mathrm{G}_{1}$ phase in NPC cells. At the molecular level, pSTAT3 was inactivated in parallel with reduced activation of the downstream anti-apoptotic proteins Survivin, Mcl-1, Bcl-2 and the cell-cycle regulatory protein Cyclin D1. Taken together, the anticancer effects of celecoxib in NPC may be partly achieved through the STAT3 pathway.

\section{Acknowledgements}

We thank Prof Ya CAO at the Cancer Research Institute of Central South University for his gift of the HNE1 and CNE1LMP1 cell lines. This project was supported by a grant from the National Natural Science Foundation of China (No 30470525).

\section{Author contribution}

Dong-bo LIU and Guang-yuan HU performed the research and wrote the manuscript; Guo-xian LONG, Hong QIU and Qi MEI performed some of the experiments and analyzed the data; and Guo-qing HU designed the experiments.

\section{References}

1 Yu MC, Yuan JM. Epidemiology of nasopharyngeal carcinoma. Semin Cancer Biol 2002; 12: 421-9.

2 Agulnik M, Epstein JB. Nasopharyngeal carcinoma: current management, future directions and dental implications. Oral Oncol 2008; 44: 617-27.

3 Teo PM, Kwan WH, Lee WY, Leung SF, Johnson PJ. Prognosticators determining survival subsequent to distant metastasis from nasopharyngeal carcinoma. Cancer 1996; 77: 2423-31.

4 Kim TH, Jeong YI, Jin SG, Pei J, Jung TY, Moon KS, et al. Preparation of polylactide-co-glycolide nanoparticles incorporating celecoxib and their antitumor activity against brain tumor cells. Int J Nanomed 2011; 6: 2621-31.

5 Zhang M, XU ZG, Shi Z, Shao D, Li O, Li W, et al. Inhibitory effect of celecoxib in lung carcinoma by regulation of cyclooxygenase-2/ cytosolic phospholipase A2 and peroxisome proliferator-activated receptor gamma. Mol Cell Biochem 2011; 355: 233-40.

6 Li H, Liu A, Zhao Z, Xu Y, Lin J, Jou D, et al. Fragment-based drug design and drug repositioning using multiple ligand simultaneous docking (MLSD): identifying celecoxib and template compounds as novel inhibitors of signal transducer and activator of transcription 3 (STAT3). J Med Chem 2011; 54: 5592-6.

7 Liu Y, Liu A, Li H, Li C, Lin J. Celecoxib inhibits interleukin-6/ interleukin-6 receptor-induced JAK2/STAT3 phosphorylation in human hepatocellular carcinoma cells. Cancer Prev Res (Phila Pa) 2011; 4: 1296-305.

8 Grösch S, Maier TJ, Schiffmann S, Geisslinger G. Cyclooxygenase-2 (COX-2)-independent anticarcinogenic effects of selective COX-2 inhibitors. J Natl Cancer Inst 2006; 98: 736-47.

9 Chen WC, McBride WH, Chen SM, Lee KF, Hwang TZ, Jung SM, et al. Prediction of poor survival by cyclooxygenase-2 in patients with T4 nasopharyngeal cancer treated by radiation therapy: clinical and in vitro studies. Head Neck 2005; 27: 503-12.

10 Peng JP, Chang HC, Hwang CF, Hung WC. Overexpression of cyclooxygenase- 2 in nasopharyngeal carcinoma and association with lymph node metastasis. Oral Oncol 2005; 41: 903-8.

11 Chen PY, Long QC. Effects of cyclooxygenase 2 inhibitors on biological traits of nasopharyngeal carcinoma cells. Acta Pharmacol Sin 2004; 25: 943-9.

12 Chan CM, Ma BB, Wong SC, Chan AT. Celecoxib induces dose dependent growth inhibition in nasopharyngeal carcinoma cell lines independent of cyclooxygenase-2 expression. Biomed Pharmacother 2005; 59: S268-71.

13 Chen J, Ran Y, Hong C, Chen Z, You Y. Anti-cancer effects of celecoxib on nasopharyngeal carcinoma HNE-1 cells expressing COX-2 oncoprotein. Cytotechnology 2010; 62: 431-8.

14 Yang J, Chatterjee-Kishore M, Staugaitis SM, Nguyen H, Schlessinger K, Levy DE, et al. Novel roles of unphosphorylated STAT3 in oncogenesis and transcriptional regulation. Cancer Res 2005; 65: 939-47.

$15 \mathrm{Yu} \mathrm{H}$, Jove R. The STATs of cancer - new molecular targets come of age. Nat Rev Cancer 2004; 4: 97-105.

16 Ma N, Kawanishi M, Hiraku Y, Murata M, Huang GW, Huang Y, et al. Reactive nitrogen species-dependent DNA damage in EBV-associated nasopharyngeal carcinoma: the relation to STAT3 activation and EGFR expression. Int J Cancer 2008; 122: 2517-25.

17 Liu YP, Tan YN, Wang ZL, Zeng L, Lu ZX, Li LL, et al. Phosphorylation and nuclear translocation of STAT3 regulated by the Epstein-Barr virus latent membrane protein 1 in nasopharyngeal carcinoma. Int J Mol Med 2008; 21: 153-62.

18 Lui VW, Wong EY, Ho Y, Hong B, Wong SC, Tao Q, et al. STAT3 activation contributes directly to Epstein-Barr virus-mediated invasiveness of nasopharyngeal cancer cells in vitro. Int J Cancer 2009; 125: 1884-93.

19 Reed S, Li H, Li C, Lin J. Celecoxib inhibits STAT3 phosphorylation and suppresses cell migration and colony forming ability in rhabdomyosarcoma cells. Biochem Biophys Res Commun 2011; 407: 450-5.

20 Raab-Traub N. Epstein-Barr virus in the pathogenesis of NPC. Semin Cancer Biol 2002; 12: 431-41.

21 Tsao SW, Tramoutanis G, Dawson CW, Lo AK, Huang DP. The significance of LMP1 expression in nasopharyngeal carcinoma. Semin Cancer Biol 2002; 12: 473-87.

22 Wang Z, Luo F, Li L, Yang L, Hu D, Ma X, et al. STAT3 activation induced by Epstein-Barr virus latent membrane protein 1 causes vascular endothelial growth factor expression and cellular invasiveness via JAK3 and ERK signaling. Eur J Cancer 2010; 46: 2996-3006 
23 Du CW, Wen BG, Li DR, Lin YC, Zheng YW, Chen L, et al. Latent membrane protein-1 of Epstein-Barr virus increases sensitivity to arsenic trioxide-induced apoptosis in nasopharyngeal carcinoma cell. Exp Oncol 2005; 27: 267-72.

24 Lin X, Liu S, Luo X, Ma X, Guo L, Li L, et al. EBV-encoded LMP1 regulates $0 p 18 /$ stathmin signaling pathway by cdc2 mediation in nasopharyngeal carcinoma cells. Int J Cancer 2009; 124: 1020-7.

25 Jendrossek V. Targeting apoptosis pathways of celecoxib in cancer. Cancer Lett 2011; doi:10.1016/j.canlet.2011.01.012.

26 Masuda M, Suzui M, Yasumatu R, Nakashima T, Kuratomi Y, Azuma $\mathrm{K}$, et al. Constitutive activation of signal transducers and activators of transcription 3 correlates with cyclin D1 overexpression and may provide a novel prognostic marker in head and neck squamous cell carcinoma. Cancer Res 2002; 62: 3351-5.

27 Shirogane T, Fukada T, Muller JM, Shima DT, Hibi M, Hirano T. Synergistic roles for Pim-1 and C-Myc in STAT3-mediated cell cycle progression and antiapoptosis. Immunity 1999; 11: 709-19.

28 Epling-Burnette PK, Liu JH, Catlett-Falcone R, Turkson J, Oshiro M, Kothapalli R, et al. Inhibition of STAT3 signaling leads to apoptosis of leukemic large granular lymphocytes and decreased Mcl-1 expression. J Clin Invest 2001; 107: 351-62.

29 Alas S, Bonavida B. Rituximab inactivates signal transducer and activation of transcription 3 (STAT3) activity in B-non-Hodgkin's lymphoma through inhibition of the interleukin 10 autocrine/paracrine loop and results in down-regulation of $\mathrm{Bcl}-2$ and sensitization to cytotoxic drugs. Cancer Res 2001; 61: 5137-44.

30 Kim KW, Mutter RW, Cao C, Albert JM, Shinohara ET, Sekhar KR, et al. Inhibition of signal transducer and activator of transcription 3 activity results in down-regulation of Survivin following irradiation. Mol Cancer Ther 2006; 5: 2659-65.

31 Xie TX, Wei D, Liu M, Gao AC, Ali-Osman F, Sawaya R, et al. Stat3 activation regulates the expression of matrix metalloproteinase-2 and tumor invasion and metastasis. Oncogene 2004; 23: 3550-60.

32 Xu Q, Briggs J, Park S, Niu G, Kortylewski M, Zhang S, et al. Targeting Stat3 blocks both HIF-1 and VEGF expression induced by multiple oncogenic growth signaling pathways. Oncogene 2005; 24: 555260.

33 Gao LF, Wen L, Yu H, Zhang L, Meng Y, Shao YT, et al. Knockdown of Stat3 expression using RNAi inhibits growth of laryngeal tumors in vivo. Acta Pharmacol Sin 2006; 27: 347-52.

34 Lui VW, Yau DM, Wong EY, Ng YK, Lau CP, Ho Y, et al. Cucurbitacin I elicits anoikis sensitization, inhibits cellular invasion and in vivo tumor formation ability of nasopharyngeal carcinoma cells. Carcinogenesis 2009; 30: 2085-94.

35 Kortylewski M, Kujawski M, Wang T, Wei S, Zhang S, Pilon-Thomas S, et al. Inhibiting Stat3 signaling in the hematopoietic system elicits multicomponent antitumor immunity. Nat Med 2005; 11: 1314-21.

36 Basu GD, Pathangey LB, Tinder TL, Gendler SJ, Mukherjee P. Mechanisms underlying the growth inhibitory effects of the cyclooxygenase-2 inhibitor celecoxib in human breast cancer cells. Breast Cancer Res 2005; 7: R422-35.

37 Levitt RJ, Buckley J, Blouin MJ, Schaub B, Triche TJ, Pollak M. Growth inhibition of breast epithelial cells by celecoxib is associated with upregulation of insulin-like growth factor binding protein-3 expression. Biochem Biophys Res Commun 2004; 316: 421-8.

38 Liu B, Shi ZL, Feng J, Tao HM. Celecoxib, a cyclooxygenase-2 inhibitor, induces apoptosis in human osteosarcoma cell line MG-63 via downregulation of PI3K/Akt. Cell Biol Int 2008; 32: 494-501.

39 Murono S, Inoue H, Tanabe T, Joab I, Yoshizaki T, Furukawa M, et al. Induction of cyclooxygenase-2 by Epstein-Barr virus latent membrane protein 1 is involved in vascular endothelial growth factor production in nasopharyngeal carcinoma cells. Proc Natl Acad Sci U S A 2001; 98: 6905-10.

40 Arico S, Pattingre S, Bauvy C, Gane P, Barbat A, Codogno P, et al. Celecoxib induces apoptosis by inhibiting 3-phosphoinositidedependent protein kinase-1 activity in the human colon cancer HT-29 cell line. J Biol Chem 2002; 277: 27613-21.

41 Monick MM, Robeff PK, Butler NS, Flaherty DM, Carter AB, Peterson MW, et al. Phosphatidylinositol 3-kinase activity negatively regulates stability of cyclooxygenase 2 mRNA. J Biol Chem 2002; 277: 329923000.

42 Bollrath J, Phesse TJ, von Burstin VA, Putoczki T, Bennecke M, Bateman T, et al. gp130-mediated Stat3 activation in enterocytes regulates cell survival and cell-cycle progression during colitis-associated tumorigenesis. Cancer Cell 2009; 15: 91-102.

43 Grivennikov S, Karin E, Terzic J, Mucida D, Yu GY, Vallabhapurapu S, et al. IL-6 and Stat3 are required for survival of intestinal epithelial cells and development of colitis-associated cancer. Cancer Cell 2009; 15 : 103-13.

44 Berishaj M, Gao SP, Ahmed S, Leslie K, Al-Ahmadie H, Gerald WL, et al. Stat3 is tyrosine-phosphorylated through the interleukin-6/ glycoprotein 130/Janus kinase pathway in breast cancer. Breast Cancer Res 2007; 9: R32.

45 Patel MI, Subbaramaiah K, Du B, Chang M, Yang P, Newman RA, et al. Celecoxib inhibits prostate cancer growth: evidence of a cyclooxygenase-2-independent mechanism. Clin Cancer Res 2005; 11 : 1999-2007.

46 Bock JM, Menon SG, Sinclair LL, Bedford NS, Goswami PC, Domann $\mathrm{FE}$, et al. Celecoxib toxicity is cell cycle phase specific. Cancer Res 2007; 67: 3801-8.

47 Sobolewski C, Cerella C, Dicato M, Diederich M. Cox-2 inhibitors induce early c-Myc downregulation and lead to expression of differentiation markers in leukemia cells. Cell Cycle 2011; 10: 2978-93.

48 Kato J, Matsushime H, Hiebert SW, Ewen ME, Sherr CJ. Direct binding of cyclin $\mathrm{D}$ to the retinoblastoma gene product $(\mathrm{pRb})$ and $\mathrm{pRb}$ phosphorylation by the cyclin D-dependent kinase CDK4. Genes Dev 1993; 7: 331-42.

49 Handrick R, Ganswindt U, Faltin H, Goecke B, Daniel PT, Budach W, et al. Combined action of celecoxib and ionizing radiation in prostate cancer cells is independent of pro-apoptotic Bax. Radiother Oncol 2009; 90: 413-21.

50 Klenke FM, Abdollahi A, Bischof M, Gebhard MM, Ewerbeck V, Huber $\mathrm{PE}$, et al. Celecoxib enhances radiation response of secondary bone tumors of a human non-small cell lung cancer via antiangiogenesis in vivo. Strahlenther Onkol 2011; 187: 45-51.

51 Kao J, Genden EM, Chen CT, Rivera M, Tong CC, Misiukiewicz K, et al. Phase 1 trial of concurrent erlotinib, celecoxib, and reirradiation for recurrent head and neck cancer. Cancer 2011; 117: 3173-81.

52 Xue WP, Bai SM, Luo M, Bi ZF, Liu YM, Wu SK. Phase I clinical trial of nasopharyngeal radiotherapy and concurrent celecoxib for patients with locoregionally advanced nasopharyngeal carcinoma. Oral Oncol 2011; 47: 753-7. 